\title{
PENINGKATAN KREATIVITAS KARANG TARUNA MELALUI PELATIHAN FOTOGRAFI UNTUK DESTINASI WISATA GEDONG PASS (G-PASS)
}

\author{
Evi Maria'1), Martin Setyawan'2), Suharyadi'1) \\ 1)Sistem Informasi Akuntansi, Fakultas Teknologi Informasi, UKSW, Salatiga, Jawa Tengah, Indonesia \\ ${ }^{2)}$ Desain Komunikasi Visual, Fakultas Teknologi Informasi, UKSW, Salatiga, Jawa Tengah, Indonesia \\ Corresponding author: Evi Maria \\ E-mail: evi.maria@uksw.edu
}

Diterima 08 September 2021, Direvisi 15 September 2021, Disetujui 17 September 2021

\begin{abstract}
ABSTRAK
Tujuan kegiatan pengabdian kepada masyarakat ini adalah untuk meningkatkan kreativitas Karang Taruna Kridha Arum sebagai pengelola destinasi wisata Gedong Pass (G-Pass) melalui pelatihan fotografi dengan keindahan alam G-Pass sebagai obyeknya. Pelatihan ini dapat membantu Karang Taruna Kridha Arum untuk dapat menyediakan foto-foto yang akan digunakan untuk promosi destinasi wisata G-Pass melalui media sosial. Pelatihan fotografi dilakukan dari tanggal 8-10 Mei 2021, setiap hari ada dua sesi, yaitu sesi pemaparan materi tentang konsep dasar fotografi dan sesi praktik fotografi, sedangkan kegiatan pendampingan fotografi dilakukan sampai akhir bulan Juni 2021 melalui grup whatsapp. Pelatihan ini diikuti oleh delapan orang pemuda Dusun Gedong yang merupakan anggota dari Karang Taruna Kridha Arum. Peserta pelatihan diberi materi dasar-dasar fotografi, terkait pengenalan fitur kamera di telepon genggam, pencahayaan, point of interest, ruang tajam dan komposisi serta proses pengunggahannya di media sosial. Setelah mengikuti pelatihan fotografi, para peserta sudah dapat menyediakan foto-foto destinasi wisata G-Pass dengan mutu visual yang baik dan sudah mengunggahnya pada media sosial baik itu media sosial milik pribadi maupun milik G-Pass untuk mempromosikan destinasi wisata G-Pass, Dusun Gedong.
\end{abstract}

Kata kunci: kreativitas; pelatihan fotografi; destinasi wisata; G-Pass

\begin{abstract}
The purpose of this community service activity is to increase the creativity of Kridha Arum Youth Organization as the manager of the Gedong Pass (G-Pass) tourist destination through photography training with the natural beauty of the G-Pass as the object. This training can help Kridha Arum Youth Organization to be able to provide photos that will be used for the promotion of G-Pass tourist destinations through social media. Photography training will be held from 8-10 May 2021, every day there are two sessions, namely a presentation session on the basic concepts of photography and a photography practice session in the area around the G-Pass, while photography assistance activities are carried out until the end of June 2021 through the whatsapp group. This training was attended by eight youths from Gedong Hamlet who are members of the Kridha Arum Youth Organization. The training participants were given the basics of photography, related to the introduction of camera features on mobile phones, lighting, point of interest, sharp space and composition as well as the process of uploading them on social media. After participating in the photography training, the participants have been able to provide photos of G-Pass tourist destinations with good visual quality and have uploaded them on social media, both personal and G-Pass social media to promote the G-Pass tourist destination, Dusun Gedong.
\end{abstract}

Kata kunci: creativity; photography training; tourist destination; G-Pass

\section{PENDAHULUAN}

Kegiatan promosi memegang peranan penting dalam menghubungkan antara produk dan konsumennya. Keberhasilan kegiatan promosi sangat ditentukan oleh kemampuan perusahaan untuk menyampaikan pesan dan keunggulan produk dan jasa tersebut pada konsumennya (Hermawan, 2012). Pesan persuasif dari produk dan jasa yang efektif diharapkan dapat membuat konsumen tertarik untuk membeli dan/atau menggunakan produk dan jasa yang diiklankan perusahaan tersebut, sehingga dapat berdampak pada peningkatan penjualan.

Tak hanya perusahaan besar, usaha kecil dan menengah juga memerlukan strategi promosi yang baik untuk bisa mendapatkan manfaat, yaitu peningkatan omset usaha. 
Namun sayangnya, Karang Taruna Kridha Arum belum memiliki kemampuan untuk mengelola kegiatan pemasaran dan promosi untuk destinasi wisata andalan Dusun Gedong, Desa Tajuk, Kecamatan Getasan, Kabupaten Semarang. Dusun ini memiliki destinasi wisata alam andalan yang diberi nama Gedong Pass atau G-Pass. Karang Taruna Kridha Arum adalah pengelola dari destinasi wisata G-Pass. Keterbatasan kemampuan mengelola pemasaran dan promosi disana, disebabkan karena kebanyakan warga disana hanya berpendidikan sampai dengan tingkat Sekolah Menengah Pertama (SMP). Kondisi ini terjadi karena letak geografis dusun ini yang berada di ketinggian $1700 \mathrm{mdpl}$ membuat infrastruktur dan fasilitas pendidikan tidak tersedia memadai disana. Keterbatasan ini, membuat promosi kebanyakan hanya dilakukan dari mulut ke mulut. Kondisi ini membuat keberadaan dan keindahan dari destinasi wisata ini belum banyak diketahui orang.

Dewasa ini, media sosial, seperti Facebook, Istagram, Twitter dan Youtube tidak hanya digunakan untuk memuaskan kebutuhan hiburan, tetapi juga digunakan sebagai media pemasaran usaha. Para pengguna media sosial dapat dengan mudah berbagi informasi dan berinteraksi. Ini yang membuat pemasaran bisnis menggunakan model ini menjadi lebih efektif dan biaya lebih murah serta penyebaran informasi menjadi lebih cepat dengan jangkauan yang lebih luas (Hiram et al., 2015; Pamungkas \& Zuhroh, 2017; Nurjanah, 2018). Media sosial tidak hanya dapat digunakan untuk mengunggah produk dan jasa yang ditawakan tetapi juga bisa menjadi media komunikasi interaktif antara pemasar dan konsumennya (Qualman, 2013). Dari unggahan di media sosial, pemasar dapat secara cepat mengetahui respon konsumen terhadap produk dan jasa yang ditawarkan melalui kolom komentar yang diunggah. Testimoni positif dari para konsumen menjadi bahan pertimbangan calon konsumen lain untuk ikut menggunakan produk dan jasa yang ditawarkan (Pamungkas \& Zuhroh, 2017).

Penelitian Umami (2015), Kurniawati (2015), dan Trihayuningtyas et al. (2019) menemukan bahwa promosi pariwisata di media sosial juga terbukti dapat meningkatkan kunjungan wisata di Yogyakarta, Grobogan dan Garut. Masyarakat dapat digerakkan untuk melakukan promosi pariwisata dengan menggunakan media sosial (Romadhan et al., 2017). Pelaku wisata dapat berinteraksi langsung dengan follower dari masing-masing pengguna media sosial serta dapat melakukan re-post ungguhan dari para pelaku wisata (Hamzah, 2013; Umami, 2015). Pengguna media sosial akan dapat saling memberi informasi tentang destinasi wisata, sehingga informasi dapat diakses masyarakat dengan cepat dan akurat. Selain itu, segmentasi dapat terbentuk dengan munculnya komunitas online di media sosial, seperti Liburan Jogja, Backpacker Dunia, dan lain-lain (Umami, 2015). Keunggulan-keunggulan inilah yang membuat destinasi wisata mulai melirik media sosial, seperti Facebook, Istagram, Twitter dan Youtube sebagai media promosi potensial, tak terkecuali pengelola destinasi wisata G-Pass, yaitu Karang Taruna Kridha Arum.

Permasalahan terkait keterbatasan kemampuan sumber daya manusia untuk mengelola promosi destinasi wisata G-Pass membuat kegiatan pengabdian masyarakat ini dilakukan. Tujuan program ini adalah untuk meningkatkan kreativitas Karang Taruna Kridha Arum melalui pelatihan fotografi dengan keindahan alam G-Pass sebagai obyeknya. Peralatan fotografi yang dipilih adalah kamera yang sudah terintegrasi dalam telepon genggam, karena mayoritas anggota Karang Taruna Kridha Arum memiliki telepon genggam dengan spesifikasi kamera yang canggih. Setelah mengikuti pelatihan fotografi, peserta pelatihan diharapkan dapat menghasilkan fotofoto keindahan alam di G-Pass dengan mutu visual yang baik dan diunggah ke sosial media sebagai bahan untuk promosi G-Pass. Selain itu, peningkatan kreativitas ini juga diharapkan dapat menciptakan peluang bisnis baru disana, yaitu menyediakan layanan dokumentasi foto untuk para wisatawan yang berkunjung ke GPass, sehingga berdampak pada peningkatan kunjungan wisata dan kesejahteraan warga Dusun Gedong.

\section{METODE}

Kegiatan pengabdian masyarakat ini dilakukan di Dusun Gedong, Kecamatan Getasan, Kabupaten Semarang. Dusun ini dipilih karena dusun ini merupakan desa mitra pengabdian masyarakat skim Program Kemitraan Masyarakat (PKM) Kemenristek/ BRIN tahun 2021. Adapun mitra kegiatan ini adalah anggota Karang Taruna Kridha Arum, yang merupakan pengelola destinasi wisata Gedong Pass (G-Pass). Sedangkan, peserta kegiatan pengabdian kepada masyarakat ini ada delapan orang pemuda yang merupakan anggota dari Karang Taruna Kridha Arum, Dusun Gedong.

Ada dua metode pelaksanaan kegiatan pengabdian kepada masyarakat ini. Pertama, pelatihan secara tatap muka yang dilakukan dari tanggal 8 sampai 10 Mei 2021. Pada tahap ini peserta diberi materi dasar-dasar fotografi, terkait pencahayaan, point of interest, ruang 
tajam dan komposisi. Setelah mendapatkan bekal materi dasar fotografi, maka dilakukan praktik fotografi secara langsung di destinasi wisata G-Pass. Kedua, pendampingan fotografi secara daring melalui grup Whatsapp dilakukan tanggal 11 Mei 2021 sampai dengan 30 Juni 2021. Pendampingan dilakukan dengan memberikan tugas-tugas fotografi yang akan dikerjakan oleh peserta pelatihan dan dibahas bersama baik oleh tutor mapun peserta dalam grup Whatsapp untuk diberikan koreksi dan masukan atas tugas yang dikerjakan oleh para peserta pelatihan. Pemberian tugas sangat penting karena memaksa peserta pelatihan untuk mempraktikkan terus materi-materi yang sudah didapatkan saat pelatihan.

Keberhasilan kegiatan pengabdian kepada masyarakat ini diukur menggunakan dua indikator. Pertama, peserta pelatihan dapat menghasilkan foto-foto dengan mutu visual yang baik terkait G-Pass. Kedua, peserta pelatihan mengunggah foto-foto dengan mutu visual baik terkait G-Pass di media sosial untuk mempromosikan destinasi wisata G-Pass.

\section{HASIL DAN PEMBAHASAN}

Peserta kegiatan pengabdian kepada masyarakat ini ada delapan orang pemuda yang merupakan anggota dari Karang Taruna Kridha Arum, Dusun Gedong. Karang Taruna ini merupakan organisasi yang menjadi pengelola destinasi wisata Gedong Pass (GPass). Kegiatan ini dilakukan untuk meningkatkan kreativitas Karang Taruna Kridha Arum untuk menghasilkan foto-foto destinasi wisata G-Pass yang memiliki mutu visual baik untuk digunakan sebagai bahan promosi di media sosial.

\section{Dasar Fotografi menggunakan Kamera Telepon Genggam}

Pelatihan fotografi dilakukan secara daring selama tiga hari, dari tanggal 8-10 Mei 2021. Ada dua sesi dalam pelatihan fotografi setiap harinya, yaitu sesi penyampaian materi dan sesi praktik fotografi. Sesi pertama dilakukan penyampaian materi terkait dasar fotografi menggunakan kamera telepon genggam. Pada sesi ini, peserta pelatihan dikenalkan fitur-fitur yang ada kamera telepon genggamnya masing-masing. Adapun fitur-fitur tersebut, antara lain (Muhyiddin, 2019):

- Grid, yaitu pengaturan kamera yang menunjukkan garis kotak yang dibentuk oleh dua garis vertikal dan horizontal untuk menilai perbandingan subjek. Garis ini fungsinya untuk menilai perbandingan subjek,

- Aspect ratio, yaitu perbandingan panjang dan lebar foto. Penggunaan fitur ini memberikan keleluasaan jika akan menghias frame foto. Kamera di telepon genggam memiliki aspect ratio 16: 9, 4:3, dan 3:2.

- Timer dan fungsinya. Timer berfungsi mengurangi goncangan kecil saat memotret. Dalam kondisi cahaya rendah dan obyek diam, maka gunakan timer 2 detik untuk memotret. Goncangan kecil pada kondisi ini dapat membuat gambar menjadi blur.

- Resolusi dan kualitas. Pemilihan pengaturan resolusi dan kualitas tinggi menyebabkan ukuran foto menjadi lebih besar. Namun demikian, foto dengan resolusi dan kualitas tinggi akan memudahkan proses editing selanjutnya. Hindari menggunakan fitur zoom camera karena akan menurunkan resolusi foto secara keseluruhan, sehingga hasil foto menjadi tidak tajam.

- Titik fokus. Biasakan menekan area yang akan menjadi fokus foto sebelum menekan tombol shutter.

- Fitur HDR untuk membuat foto lebih tampak seimbang antara daerah gelap dan terang.

- Flash, sebagai bantuan pencahayaan ketika kondisi gelap atau pencarian titik fokus.

Setelah pengenalan fitur kamera telepon genggam, peserta pelatihan mulai dikenalkan teknik memotret, antara lain sebagai berikut:

- Tentukan tipe shoot ketika memotret sesuai dengan tema. Ada tiga macam tipe, yaitu

1. Long shoot, yaitu pengambilan gambar hanya menggunakan area subyek tanpa terpotong frame. Tipe ini biasa digunakan untuk memotret papan nama dan pemandangan alam, supaya informasi yang akan disampaikan tidak terpotong.

2. Medium shoot, yaitu pengambilan gambar jarak menengah, dengan batas pemotongan obyek adalah dari bagian pinggang ke atas.

3. Close up, yaitu pengambilan gambar dari jarak dekat dan fokus pada bagian tertentu.

- Memotret harus mengikuti arah cahaya, supaya obyek utama yang akan difoto dapat pencahayaan yang baik, sehingga informasi foto tersampaikan dengan baik.

- Peganglah telepon genggam dengan kedua tangan dan siku menempel di badan. Ini berfungsi untuk meredam getaran dan mencegah hasil foto yang blur. 
- Ketika memotret, garis horizontal dan garis vertikal harus sewajarnya ditampilkan harus datar atau lurus.

- Aktifkan fitur grid dari pengaturan telepon genggam dan gunakan ketika memotret, supaya foto yang dihasilkan menjadi lebih estetis dan rapi.

- Pastikan, obyek utama yang akan di foto tidak terpotong atau utuh, sehingga informasi dapat tersampaikan dengan lengkap.

- Ketika akan memotret, perhatikan latar belakang dan latar depan, usahakan tidak ada obyek yang mengganggu.

Selain secara teori dalam pelatihan ini ditunjukan juga contoh-contoh foto dengan mutu visual yang baik dan bisa menyampaikan pesan atau cerita, supaya foto-foto yang nantinya akan dihasilkan oleh peserta bisa lebih bercerita tentang G-Pass dan lebih persuasif. Gambar 1 menampilkan suasana pelatihan saat sesi pemaparan materi dasar fotografi

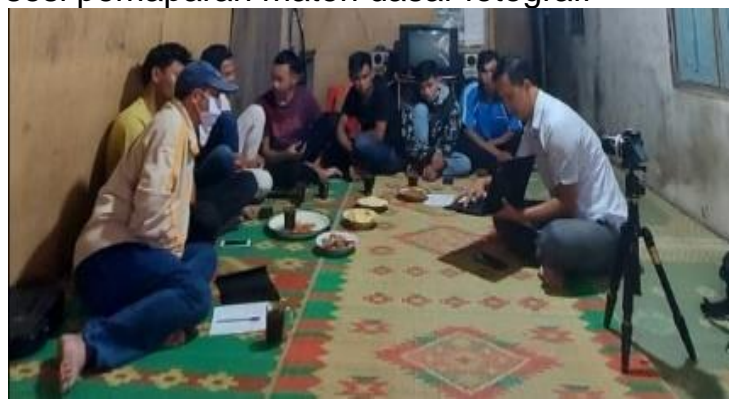

Gambar 1. Suasana pelatihan fotografi di Dusun Gedong

Setelah sesi penyampaian materi, peserta pelatihan mengikuti sesi praktik secara langsung di lokasi destinasi wisata G-Pass. Sesi praktik ini dilakukan selama tiga hari, mulai tanggal 8-10 Mei 2021. Dalam kegiatan praktik ini, peserta pelatihan mencoba mempraktikan materi yang telah diterima saat sesi pemaparan materi. Dalam sesi ini, tutor memberikan contoh, mendampingi secara langsung dan mengkoreksi hasil, seperti yang terlihat pada Gambar 2.



Gambar 2. Praktik Fotografi di Dusun Gedong

\section{Pendampingan Kegiatan Fotografi}

Kegiatan pengabdian kepada masyarakat ini tidak hanya dilakukan dengan metode pelatihan, tetapi juga menggunakan metode pendampingan secara daring. Pendampingan secara daring dilakukan dari 11 Mei 2021 sampai dengan 30 Juni 2021. Interaksi antara peserta pelatihan dan tutor dilakukan melalui media chatting di grup Whatsapp. Interaksi anatar peserta dan tutor terjadi cukup intensif meskipun dilakukan secara daring. Ini karena peserta sangat antusias dalam mengikuti pelatihan dan pendampingan fotografi. Di sesi pendampingan daring, Tutor memberikan tugas-tugas fotografi yang akan dikerjakan oleh peserta pelatihan dan dibahas bersama dalam grup Whatsapp untuk diberikan koreksi dan masukan. Pendampingan fotografi secara daring dapat dilihat pada Gambar 3.

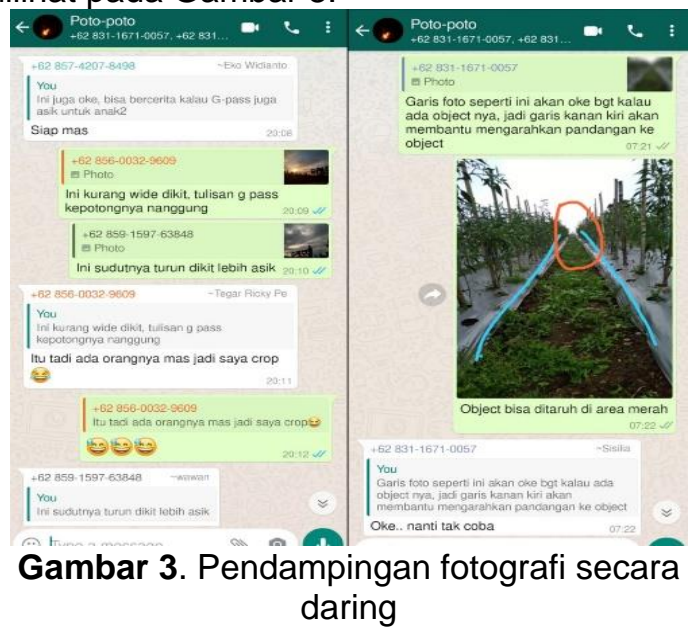

\section{Capaian Kegiatan Pengabdian Kepada Masyarakat}

Setelah mengikuti kegiatan pelatihan fotografi ini, peserta pelatihan sudah dapat menghasilkan foto-foto destinasi G-Pass dengan mutu visual yang baik meskipun hanya menggunakan peralatan fotografi sederhana, yaitu kamera yang terintegrasi dalam telepon genggam. Hasil foto peserta pelatihan dapat dilihat pada Gambar 4 dan 5. 




Gambar 4. Hasil foto peserta pelatihan fotografi

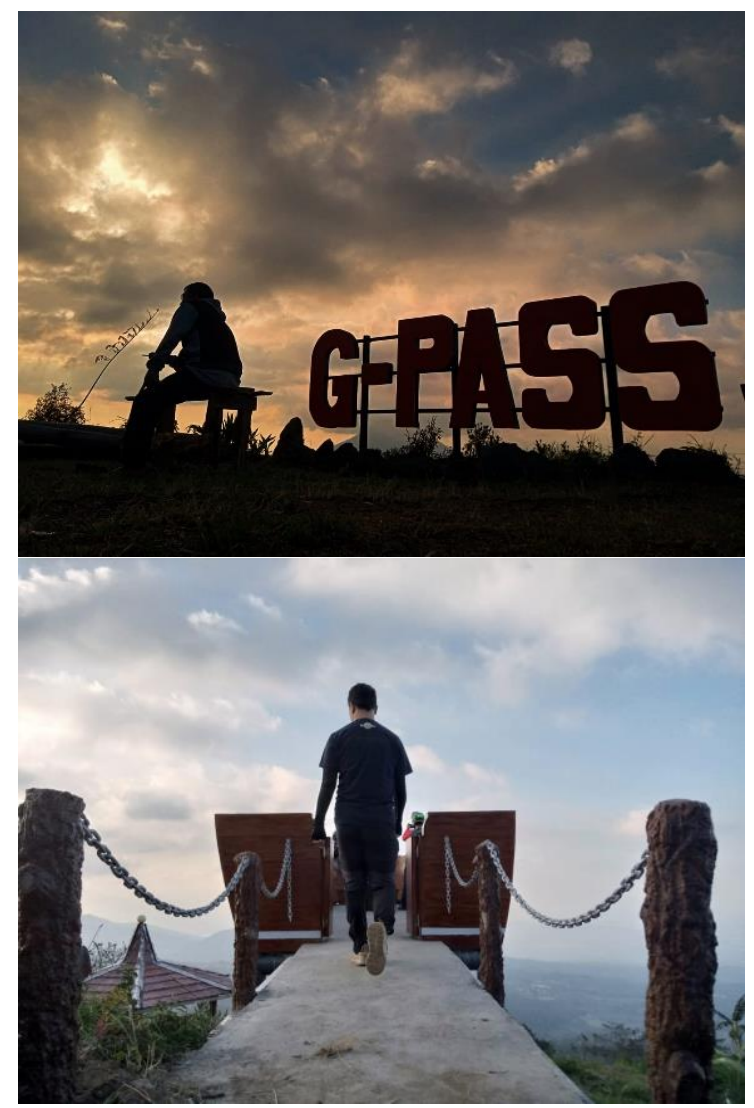

Gambar 5. Hasil foto peserta pelatihan fotografi

Peserta pelatihan sudah mengunggah foto-foto dengan mutu visual yang baik di media sosial milik pribadi maupun media sosial milik G-Pass. Upload foto yang dilakukan perserta kegiatan juga sudah disertai dengan narasi untuk mempromosikan potensi yang ada di Dusun Gedong. Tujuannya, agar pengujung tertarik datang ke G-Pass dan Dusun Gedong. Unggahan hasil foto peserta pelatihan di media sosial G-Pass dapat dilihat pada Gambar 6
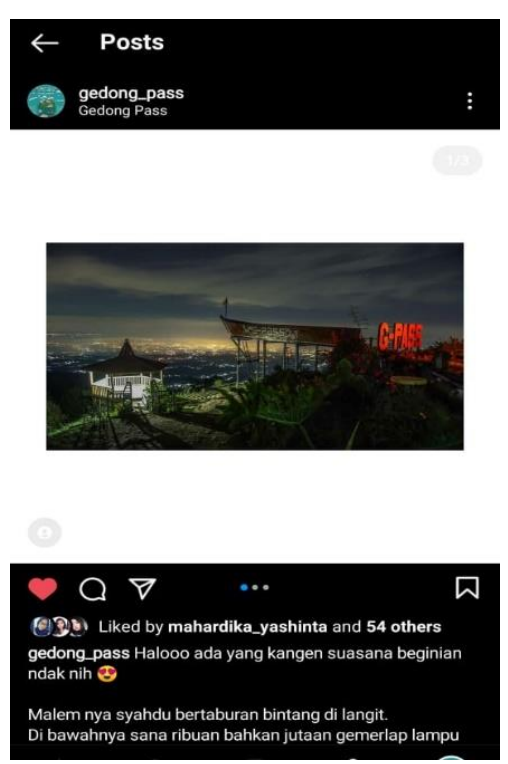

Gambar 6. Unggahan hasil foto peserta pelatihan fotografi di media sosial G-Pass

\section{SIMPULAN DAN SARAN}

Hasil kegiatan pengabdian kepada masyarakat ini adalah peningkatan kreativitas Karang Taruna Kridha Arum untuk menghasilkan foto-foto destinasi wisata G-Pass dengan mutu visual yang baik dalam rangka promosi destinasi wisata G-Pass di media sosial. Peserta pelatihan sudah dapat menghasilkan foto-foto destinasi wisata G-Pass dengan mutu visual yang baik. Peserta kegiatan pelatihan fotografi sudah berhasil menggunakan teknik memotret menggunakan kamera yang terintegrasi dalam telepon genggam untuk menghasilkan foto dengan mutu visual yang baik. Ini terlihat dari unggahan foto-foto destinasi wisata G-Pass di media sosial, baik itu media sosial pribadi maupun media sosial milik G-Pass.

Namun, masih ada hambatan yang dihadapi Karang Taruna Kridha Arum terkait promosi destinasi wisata. Karang Taruna Kridha Arum masih mengalami kesulitan untuk mengelola media sosial yang terintegrasi. Akun-akun media sosial G-Pass belum terintegrasi sehingga membutuhkan waktu lama untuk mengunggah foto dan berita promosi G-Pass pada seluruh akun media sosial G-Pass. Oleh sebab itu, kegiatan pelatihan untuk pengelolaan media sosial perlu untuk dilakukan bagi Karang Taruna Kridha Arum.

\section{UCAPAN TERIMAKASIH}

Terimakasih kepada Kemenristek/ BRIN atas bantuan pendanaan untuk menjalankan kegiatan pengabdian kepada masyarakat dalam Program Kemitraan Masyarakat tahun 2021. 


\section{DAFTAR RUJUKAN}

Hamzah, Y. I. (2013). Potensi Media Sosial Sebagai Sarana Promosi Interaktif Bagi Pariwisata Indonesia. Jurnal Kepariwisataan Indonesia, 8(3), 1-9. http://www.kemenpar.go.id/userfiles/JKI Vol 8 No 32013 - Potensi Media Sosial Sebagai Sarana Promosi Interaktif Bagi Pariwisata Indonesia.pdf

Hermawan, A. (2012). Komunikasi Pemasaran. Jakarta: Erlangga.

Hiram, T., Winnie, W. P. ., Ernest, C. D. R., \& Sally, L, Y, C. (2015). Beliefs sbout the Use of Instagram: An Exploratory Study. International Journal of Business and Innovation, 2(2).

Kurniawati, W. D. N. (2015). Pemanfaatan Instagram oleh Komunitas Wisata Grobogan dalam Mempromosikan Potensi Pariwisata Daerah. Komuniti : Jurnal Komunikasi Dan Teknologi Informasi, 8(2), 127-143. https://doi.org/https://doi.org/10.23917/ko muniti.v8i5.2943

Muhyiddin, A. (2019). MODUL PELATIHAN: Membuat Media Promosi Dan Kehumasan Dengan Ponsel Pintar. USAID.

Nurjanah, N. (2018). Pemanfaatan Media Sosial Masyarakat Sadar Wisata Dalam Mempromosikan Potensi Wisata Baru. Medium, 6(2), 39-50. https://doi.org/10.25299/medium.2018.vol 6(2).2412

Pamungkas, B. A., \& Zuhroh, S. (2017). Pengaruh Promosi Di Media Sosial Dan Word of Mouth Terhadap Keputusan Pembelian (Studi Kasus Pada Kedai Bontacos, Jombang). Jurnal Komunikasi, 10(2), 145-159. https://doi.org/10.21107/ilkom.v10i2.2518

Qualman, E. (2013). Socialnomics: How social media transforms the way we live and do business. Canada: John Wiley \& Sons, Inc.

Romadhan, M. I., Sri, D., \& Rusmana, A. (2017). Potensi Media Sosial Sebagai Sarana Media Promosi Pariwisata Berbasis Partisipasi Masyarakat. Prosiding Seminar Dan Call For Paper, 85-90.

Trihayuningtyas, E., Wulandari, W., Adriani, Y., \& Sarasvati, S. (2019). Media Sosial Sebagai Sarana Informasi Dan Promosi Pariwisata Bagi Generasi Z Di Kabupaten Garut. Tourism Scientific Journal, 4(1), 1. https://doi.org/10.32659/tsj.v4i1.46

Umami, Z. (2015). Social Strategy Pada Media Sosial Untuk Promosi Pariwisata Daerah Istimewa Yogyakarta. INTERAKSI: Jurnal
IImu Komunikasi, 4(2), 195-201. https://doi.org/10.14710/interaksi,4,2,195201 